\title{
Atividades de extensão no IFRJ - Campus Duque de Caxias: a música em pauta
}

\section{Community work in IFRJ - Duque de Caxias Campus: music on the agenda.}

Jupter Martins de Abreu Júnior ${ }^{1}$

1 Professor. Instituto Federal de Educação, Ciência e Tecnologia do Rio de Janeiro (IFRJ), Brasil. E-mail: jupter.junior@ifrj.edu.br

Recebido em: 31/03/2015 | Aprovado em: 06/10/2015

DOI: $10.12957 /$ interag.2016.15575

\begin{abstract}
Resumo
O trabalho visa descrever algumas atividades de extensão relacionadas à música que são desenvolvidas no IFRJ - Campus Duque de Caxias. As atividades musicais inseridas nessa proposta têm como base a Lei $n^{\circ} 11.769 / 08$, que estabelece a obrigatoriedade do ensino de Música na educação básica, os referenciais de Kater, Sobreira, além de Penna, Barros e Mello. Os procedimentos metodológicos consistem na realização de oficinas de Teoria e Percepção Musical, Prática de Conjunto, Sonorização Básica e Editoração de Partituras. Essas atividades de extensão são realizadas no campus, com a participação de alunos, ex-alunos, servidores e comunidade externa, e têm a finalidade de qualificar os participantes a estruturar todas as etapas inerentes à realização do projeto de extensão, desde a parte de preparação dos equipamentos de áudio até o produto final, que são as apresentações musicais. As principais contribuições consistem na interação entre os participantes do projeto, além de constituir o cerne formador de um grupo musical oficial do IFRJ, o qual pode se tornar uma importante ferramenta de divulgação da instituição no município de Duque de Caxias. Como consequência desse trabalho, pretende-se estruturar um núcleo de cultura no campus, realizando de maneira concreta uma proposta de política cultural no IFRJ.
\end{abstract}

Palavras-chave: Música, IFRJ, Duque de Caxias.

Área temática: Cultura.

Linha de extensão: Música.

\begin{abstract}
This paper aims to describe some community activities that promote the learning of music developed in IFRJ Duque de Caxias Campus. Music activities in this proposal are based on the Law No. 11.769 108, which establishes mandatory Music teaching in basic education. Also, they are based on references such as Kater, Sobreira, besides Penna, Barros and Mello. The methodological procedures consist in Theory and Music Perception workshops, Ensemble, Basic Sound and Score Writing. These activities are held on campus, with the participation of students, former students, employees, and the outside community. They aim to qualify participants to structure all the steps involved in completion of the community project, from the preparation of the audio equipment to the final product, that is, the musical performances. The main contributions of these community activities consist of the interaction between the project participants, besides being the forming heart of an official musical group of IFRJ, which can become an important marketing tool of the institution in the municipality of Duque de Caxias. As a result of this project, we intend to structure a core culture group on campus, performing in a concrete way a draft cultural policy in IFRJ.
\end{abstract}

Keywords: Music; IFRJ; Duque de Caxias.

\section{Introdução}

A Música, além de área de conhecimento e linguagem artística presente no cotidiano das pessoas, constitui-se uma prática social produzida e vivida por diversos segmentos 
da sociedade, sendo por isso considerada instância privilegiada de socialização, na qual é possível exercitar as capacidades de ouvir, compreender e respeitar o outro. Assim, concordamos com Kater ${ }^{1}$, quando este diz que "a educação musical representa uma alternativa prazerosa e especialmente eficaz de desenvolvimento individual e de socialização”.

A partir dessas premissas, cabe destacar que o Instituto Federal de Educação, Ciência e Tecnologia do Rio de Janeiro (IFRJ) - Campus Duque de Caxias, tem uma vocação muito expressiva para atividades musicais. Podemos observar que discentes, docentes, técnicos, funcionários terceirizados e comunidade externa têm um grande interesse pelas atividades relacionadas à música ou mesmo já têm experiência anterior em práticas musicais, seja tocando algum instrumento ou mesmo cantando. Dessa forma, as ações apresentadas neste texto, entre as quais se destaca o projeto "Música e inclusão social no bairro do Sarapuí/Duque de Caxias", têm como principal meta integrar a comunidade local à instituição de ensino, fomentando atividades culturais extensivas às comunidades interna e externa. Com estas ações, pretende-se incentivar a criação e o desenvolvimento de grupos musicais que tenham condições de realizar apresentações para a comunidade local e/ou externa, divulgando e valorizando as atividades culturais na instituição e nas comunidades próximas ao campus da instituição. Inserido nesse contexto, o presente trabalho pretende descrever as propostas e ações de extensão relacionadas às diversas formas de prática musical que são desenvolvidas no IFRJ - Campus Duque de Caxias, localizado na Baixada Fluminense.

\section{Questões sobre o ensino de música nas escolas: caminhos a serem percorridos}

Enquanto lócus das atividades ora apresentadas, é relevante apontar que a Baixada Fluminense, mais especificamente o município de Duque de Caxias, destaca-se na Região Metropolitana do Rio de Janeiro como grande centro econômico e industrial, sendo o $3^{\circ}$ maior Produto Interno Bruto (PIB) do estado. Apesar do grande desenvolvimento econômico alcançado nos últimos anos, em outros setores existentes, como é o caso da parte cultural e social, vê-se que o município tem muitas lacunas a 
serem preenchidas e que a população, de uma maneira geral, não tem acesso a uma vivência cultural mais ampla, ficando restrita apenas aos elementos divulgados pelos meios de comunicação de massa. Por outro lado, conforme afirma Marques², existe um número significativo de talentos musicais e de produção musical na região, fato que potencializa a realização de um trabalho efetivo no contexto de inclusão social e ampliação cultural associado à área da Música.

Em concomitância às questões apresentadas, destaca-se que o ano de 2008 tornou-se um marco histórico no contexto de institucionalização da Música no meio escolar, pois nesse ano foi aprovada a Lei . $^{\circ} 11.769^{3}$, a qual determina a obrigatoriedade do ensino de Música na educação básica. Também deve ser considerado como significativo na citada lei o fato de que as instituições de ensino tiveram três anos para se adequar às obrigações previstas, ou seja, a partir do ano de 2011 a lei deveria ser cumprida de maneira efetiva. Entretanto, conforme afirma Sobreira ${ }^{4}$, devido a fatores diversos, como a falta de professores formados na área, ausência de espaço adequado para a prática musical, entre outros motivos, a lei não tem sido cumprida de forma adequada. Apesar desses aspectos, a aprovação da lei mostra que há no atual contexto brasileiro uma clara tendência dos órgãos governamentais e da sociedade como um todo em apoiar empreendimentos relacionados a essa linguagem artística.

Entretanto, para que se obtenham bons resultados em atividades com foco em práticas musicais, é necessário que o aluno tenha acesso a conhecimentos específicos, como teoria e percepção musical, prática de conjunto e prática instrumental. Essas atividades constituem o núcleo básico necessário para o domínio da linguagem musical, sendo elementos fundamentais para o desenvolvimento de uma formação musical sólida. A existência dessas ações reunidas num mesmo projeto torna a realização da prática musical uma atividade completa, já que tanto as ações no contexto de práticas musicais, quanto de práticas sociais estariam sendo contempladas de uma maneira efetiva. É nessa conjuntura que emerge a necessidade da participação de comunidades vizinhas no âmbito escolar através da Música e a consequente aproximação entre os indivíduos destas comunidades no espaço escolar.

Interagir: pensando a extensão, Rio de Janeiro, n. 21, p. 93-101, jan./jun. 2016 


\section{A participação da comunidade e as potencialidades da Música: aspectos presentes}

A participação da comunidade na escola está prevista de uma maneira mais efetiva nas leis brasileiras desde a Constituição de $1988^{5}$, e como complemento o Estatuto da Criança e do Adolescente (ECA) também estabelece que a educação deva ser incentivada e promovida com a colaboração da sociedade. Dentro desse contexto, tendo em vista que a Música é um dos mais importantes instrumentos de integração social existente e que a inclusão tem sido um objetivo comum à sociedade brasileira, as atividades desenvolvidas no projeto "Música e inclusão social no bairro do Sarapuí/Duque de Caxias“ vêm oferecendo uma oportunidade significativa de integração entre os músicos dessa comunidade, bem como uma forma de especialização para possíveis inserções nas áreas de atuação relacionadas às práticas musicais.

Assim, observa-se que nesta proposta as iniciativas têm por meta desenvolver habilidades e competências que possam sustentar uma produção musical consistente, e assim, os resultados dos trabalhos, os quais podem ser de cunho individual ou mesmo realizados em grupo, podem tornar-se visíveis, valorizados e reconhecidos, e todo esse processo articulado leva a uma auto percepção positiva dos grupos, indispensável para o fortalecimento da autoestima ${ }^{6}$.

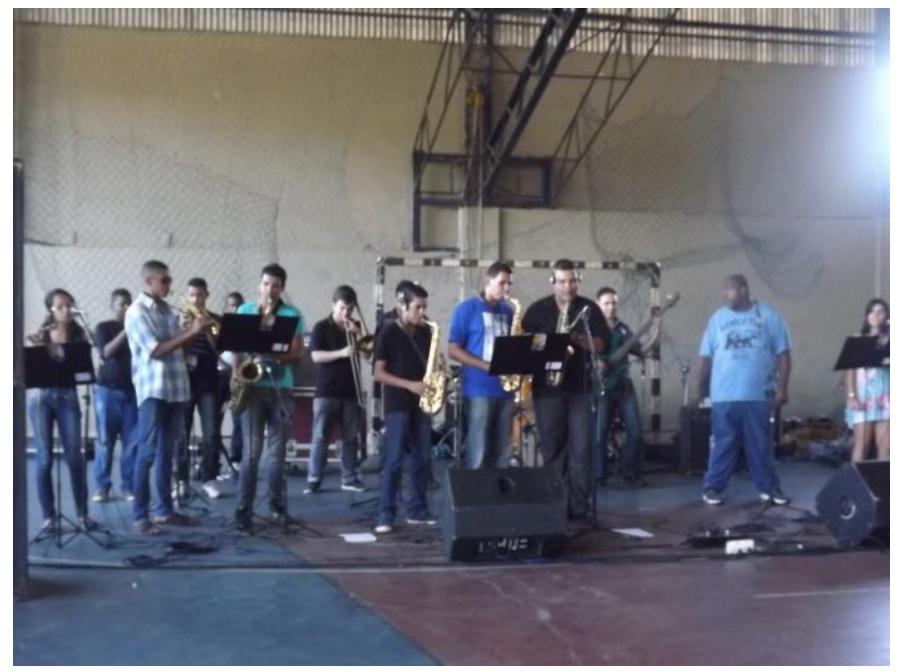

Figura 1. Apresentação no Encontro de Ex-alunos do IFRJ/Campus Nilópolis.

Os percursos do projeto: pontos de partida e tentativas de chegada 
Como ponto de partida do projeto, inicialmente tem sido feita a sua divulgação na comunidade interna e junto a alguns segmentos das comunidades próximas (escolas, igrejas, academias, associações de moradores). Na divulgação já são informados os dias e horários da realização das atividades, em que o público externo que vem à instituição objetivando participar de alguma oficina normalmente conhece algum aluno, ex-aluno ou funcionário da instituição, sendo raras as exceções a esses casos.

As oficinas de Teoria e Percepção Musical têm acontecido de forma esporádica, principalmente quando ocorrem os eventos de extensão no campus. Entretanto, existe a possibilidade que as oficinas de Teoria e Percepção Musical se tornem quinzenais, devido às solicitações dos próprios alunos, que ao terem contato com a atividade nos eventos, observaram que estas são uma ferramenta importante para potencializar os seus conhecimentos musicais.

As oficinas de Prática de Conjunto são quinzenais, com carga horária de 4 horas, sendo compostas pelos seguintes instrumentos: saxofone, trombone, trompete, percussão, bateria, flauta transversa, violão, teclado e guitarra. Tanto para as atividades de Prática de Conjunto quanto para as oficinas de Teoria e Percepção Musical tem sido utilizada a sala do Núcleo de Estudos Afro-Brasileiros e Indígenas (NEABI), a qual se localiza em um prédio anexo. É relevante observar que esta sala, por ser afastada do local onde são ministradas a grande maioria das aulas, possibilita a realização dessas atividades. Este fato tem relevância na medida em que a produção do som em alta intensidade certamente prejudicaria o bom andamento das atividades docentes, causando constrangimentos para ambas as partes. É importante destacar que este aspecto fragiliza a realização de atividades musicais em diversas instituições, devido à inexistência de espaço físico adequado a essas práticas, as quais têm o som como elemento básico para sua efetivação. 


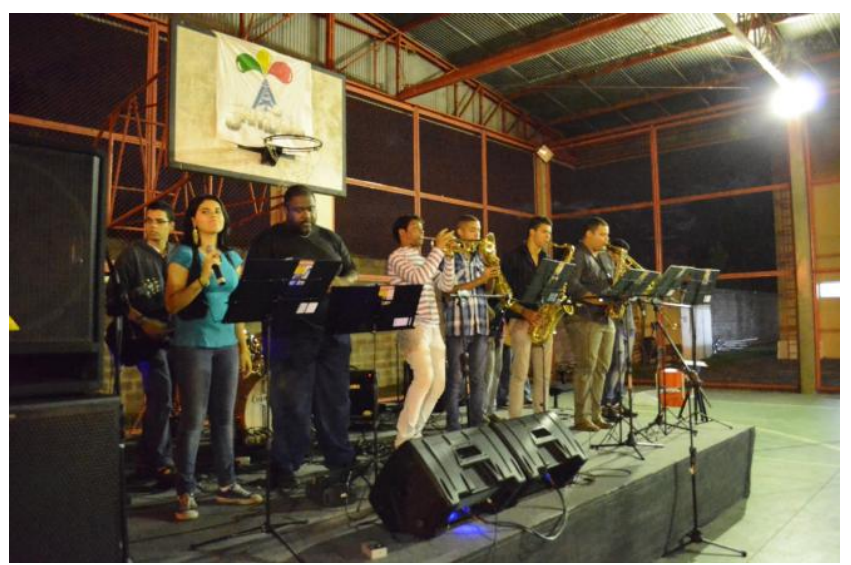

Figura 2. Apresentação Musical no Projeto Conexões - Auditório do IFRJ - Campus Nilo Peçanha/Pinheiral.

Como atividades complementares, são realizadas oficinas de Sonorização Básica e Editoração de Partituras, as quais têm gradativamente aumentado a sua oferta, devido às necessidades do projeto, que dependem destas atividades para o seu bom andamento. A Oficina de Sonorização Básica visa à realização de pequenos reparos e manutenção preventiva nos equipamentos de som, além da verificação e montagem de todo o equipamento necessário para a realização de apresentações musicais do campus. No caso da Editoração de Partituras, é realizado todo um processo artesanal de escrita de partituras e seleção de repertório, que apesar de ter como ferramenta um editor de partituras, ainda necessita de várias etapas em que a existência de uma equipe de suporte é de relevante importância para viabilizar a produção das partituras para os diferentes instrumentos musicais existentes no grupo. Esse aspecto é de grande relevância, principalmente no caso dos instrumentos de sopro (sax alto, sax soprano, sax tenor, trombone, trompete, flauta transversal), que possuem questões específicas na sua escrita.

\section{Discussões a partir das atividades realizadas}

Considerando-se que a presente proposta tem sido realizada desde o ano de 2012, observa-se um crescimento substancial nas atividades relacionadas às práticas musicais no IFRJ - Campus Duque de Caxias, com o aumento gradativo no interesse dos diversos segmentos da comunidade interna (alunos, docentes, técnicos e outros) por essas atividades. Uma das questões relevantes que pode ser apontada com relação à 
presente proposta é o processo de legitimação das Artes no campus, que vem ocorrendo gradativamente, na medida em que se identifica certo reconhecimento de professores e servidores em geral com relação às práticas musicais realizadas. Essa legitimação pode ser materializada no apoio recebido pelas atividades artísticas, além de ser observada na ampliação do nível cultural e artístico dos participantes, destacando-se as apresentações dos grupos musicais surgidos no campus em eventos internos e externos. Nas atividades do projeto em andamento também pode ser observada a capacitação do material humano na área da Música, conforme demonstram as necessidades surgidas a partir da regulamentação da Lei n. ${ }^{\circ}$ 11.769/08, sendo que, no caso aqui descrito, a finalidade é qualificar os participantes a estruturar todas as etapas inerentes à realização de projetos de extensão relacionados à Música, desde a manutenção e preparação dos equipamentos de áudio e instrumentos musicais até o produto final, que são as apresentações artísticas.

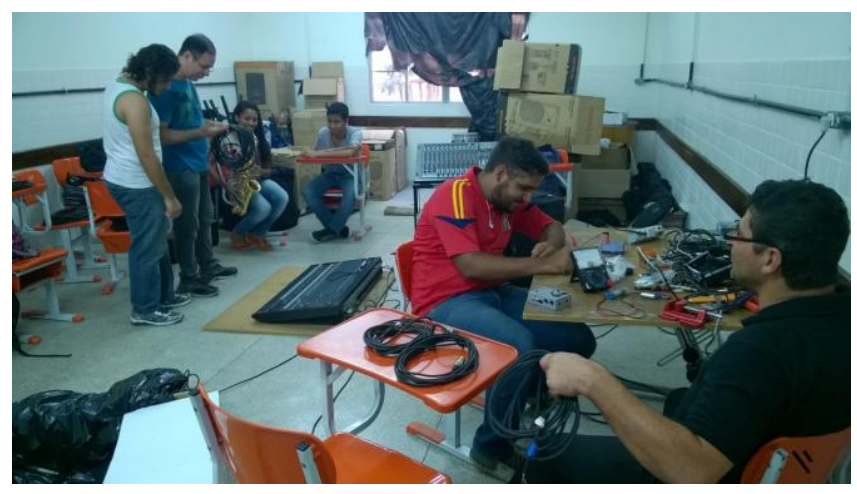

Figura 3. Oficina de Sonorização Básica.

A participação dos alunos, ex-alunos, docentes, técnicos administrativos, funcionários terceirizados e comunidade externa nas atividades de extensão da instituição, integrando-os ao IFRJ - Campus Duque de Caxias, é uma característica marcante nas atividades do projeto aqui descrito, em que se pretende a sua ampliação na medida em que é visualizado o potencial agregador de valores existente na proposta. Nesse contexto, deve ser considerado que, embora o IFRJ esteja presente no município de Duque de Caxias desde setembro de 2006, época em que ainda era denominado CEFET-Química, é fato que a instituição ainda carece de divulgação e reconhecimento no âmbito do município. Assim, essas atividades com cunho extensionista certamente auxiliam na visibilidade institucional junto à população, ampliando as possibilidades de 
que, além de uma escola técnica, o IFRJ/Campus Duque de Caxias também se torne uma instituição de fomento às atividades culturais locais.

\section{Ampliação da proposta: novos desafios}

Com o intuito de suscitar novas iniciativas, pode-se refletir quanto aos trabalhos futuros que poderão surgir do presente projeto, e entre esses pode ser destacada a proposta de um livro de Transcrição de Arranjos para Música Popular Brasileira, o qual seria um material surgido a partir das transcrições dos arranjos produzidos ao longo da trajetória do projeto, arranjos estes que alimentam o repertório desenvolvido pelo grupo musical formado na proposta.

Com relação às possibilidades de ampliação do projeto, se encontra em estudo a oferta de cursos no formato PRONATEC-Formação Inicial e Continuada (FIC), oferecidos na categoria "Músico de Banda". Estes cursos, caso sejam viabilizados, têm condições de ampliar as potencialidades do presente projeto, tornando-o acessível a um número maior de sujeitos das comunidades interna e externa, efetivando de maneira concreta o alcance do projeto.

Quanto a outras iniciativas de potencializar as atividades artísticas na instituição, destaca-se a proposta do estabelecimento de um Núcleo de Cultura no IFRJ - Campus Duque de Caxias. Essa ação se encontra inserida no Plano de Cultura da instituição, documento que já possui uma proposta inicial e se encontra em fase de novas discussões. Assim, o Núcleo de Cultura do IFRJ/Duque de Caxias seria composto, inicialmente, pelas atividades de Música e Teatro, sendo que na parte da Música seriam incluídas como proposta a banda, que se encontra em desenvolvimento por meio do projeto "Música e inclusão social no bairro do Sarapuí/Duque de Caxias“, além de uma orquestra do tipo big-band, formada por instrumentos de base (guitarra, teclados, baixo, bateria, percussão) e sopros (trombones, trompetes, saxofones, flautas transversais), contemplando inclusive alguns instrumentistas do projeto em andamento. Também fariam parte dessa etapa de ampliação as propostas de formação de um grupo de percussão e um coral, que teriam o trabalho integrado às propostas da banda e da orquestra, ratificando o espaço das Artes na instituição, suscitando assim um novo olhar para essa área de conhecimento no IFRJ. 


\section{Agradecimentos}

Nós, integrantes do projeto "Música e inclusão social no bairro do Sarapuí/Duque de Caxias", agradecemos ao apoio da Pró-Reitoria de Extensão do IFRJ, que por meio do Programa Institucional de Incentivo às Atividades de Extensão (Pró-Extensão) e do Programa Institucional de Bolsas de Incentivo às Atividades de Extensão (PIBIEX), muito tem nos ajudado na realização da proposta.

\section{Referências}

1. KATER, Carlos. O que podemos esperar da educação musical em projetos de ação social. Revista da ABEM, Porto Alegre, v. 10, p. 43-51, mar. 2004. Disponível em <http.abemeducacaomusical.org.br>. Acesso em: 07 ago. 2015.

2. MARQUES, Alexandre dos Santos. Militantes da cultura numa área periférica. Dissertação (Mestrado em História). Universidade Severino Sombra, Vassouras, 2005

3. BRASIL. Lei n. ${ }^{\mathbf{1 1 . 7 6 9}}$, de 18 de agosto de 2008. Trata da obrigatoriedade do ensino de música na educação básica. Brasília, DF, 2008.

4. SOBREIRA, Silvia Garcia. Disciplinarização do ensino de Música e produção de sentidos sobre Educação Musical: investigando o papel da ABEM no contexto da Lei n. ${ }^{\mathbf{0}}$ 1 1.769/2008. Tese (Doutorado em Educação). UFRJ, Rio de Janeiro, 2012.

5. BRASIL. Constituição Federal do Brasil. Brasília, DF, 1988.

6. PENNA, Maura; BARROS, Olga Renalli Nascimento e; MELLO, Marcel Ramalho. Educação musical com função social: qualquer prática vale? Revista da ABEM, Porto Alegre, v. 20, p. 65-78, jan-jun. 2012. Disponível em: $<$ http.abemeducacaomusical.org.br>. Acesso em: 05 ago. 2015. 